\title{
Colaboração Externa no Processo de Inovação de uma Fashion Industry
}

\author{
External Collaboration in the Innovation Process of a Fashion Industry
}

\section{Resumo}

Sidney Matos Mendes ${ }^{\mathrm{I}}$

Este artigo busca contribuir com os estudos de inovação aberta, inovação global e processos de desenvolvimento de produto. Foi pesquisada a colaboração de fornecedores externos sobre o processo de inovação de uma organização; o que foi entendido como uma atuação de inovação aberta. Sendo a fashion industry parte de organizações que entregam constante inovações, foi escolhida, como objeto de estudo para este artigo, uma organização internacional que tem uma subsidiária no estado de São Paulo. Foram entrevistados seis profissionais que atuavam diretamente no processo de desenvolvimento das coleções. Fazendo uso de abordagem metodológica qualitativa, com método de estudo de caso e análise de conteúdo para tratamento dos dados, constatou-se que ocorre a independência de atuação e adoção da inovação aberta entre as diferentes fases do processo de inovação.

Palavras-chave: Colaboração Externa; Processo de Inovação; Fashion Industry.

\begin{abstract}
This article aims to contribute to the studies of open innovation, the global innovation, and product development processes. The collaboration of external suppliers in the innovation process of an organization was researched; which was understood as an open innovation performance. As the fashion industry makes part of the organizations that deliver constant innovations, it was chosen, as a study object for this article, an international organization that has a subsidiary in the state of São Paulo. Six professionals were interviewed. They were directly involved in the clothing development. Using a qualitative methodological approach, with case study method and content analysis for data treatment, it was verified that the independence of action and adoption of open innovation occurs along the different phases of the innovation process.
\end{abstract}

Keywords: External Collaboration; Innovation Process; Fashion Industry.

\footnotetext{
1 sidneymatos@gmail.com, Brasil. Professor do Centro Universitário das Faculdades Metropolitanas Unidas - FMU. Mestre em Gestão Internacional pela Escola Superior de Propaganda e Marketing - ESPM. Av. Lins de Vasconcelos, 3406, Vila Mariana, CEP: 04112-002 - São Paulo, SP - Brasil.
}

Recebido em 02.10.2017

Aprovado em 15.12.2017

\section{Revista Administração em Diálogo}

ISSN 2178-0080 


\section{Introdução}

O processo de inovação (PI) é adotado por organizações quando atuam em ambientes de alta competitividade (Silva, Bagno \& Salerno, 2013) na busca por produção e manutenção de um diferencial competitivo. Por não haver um modelo teórico homogêneo para todos os setores industriais, buscar-se-á a descrição dos mais significativos e implementados, entre eles: o Funil da Inovação, o Stage-Gate- filtros de qualificação -, a Cadeia de Valor, a Inovação Aberta e o Fluxo da Inovação Global. Partindo da compreensão desses modelos e da dificuldade de adoção de um único modelo útil para ambientes sujeitos a colaborações externas nacionais e internacionais, é questionada qual a influência da colaboração externa no processo de desenvolvimento de produto inovador. Para responder a tal pergunta, estabeleceu-se o objetivo principal de analisar como o PI pode se adaptar à desagregação da propriedade com influência de colaboradores externos. Em correspondência a esse objetivo, estabeleceu-se como objetivos secundários: i) a elaboração de um modelo PI que pode ser adotado em ambientes colaborativas; ii) a identificação da atuação dos colaboradores externos no PI, abertura do escopo proprietário; e iii) validação de um modelo de framework com fases independentes na atuação proprietária, ocorrendo uma desagregação do escopo proprietário.

Para atingir esses objetivos, utilizou-se a abordagem metodológica qualitativa, que permitiu a coleta de dados necessária para a realização de um estudo de caso único seguindo o modelo de Eisenhardt (I989). Nessa coleta de dados, fez-se uso de questionários semiestruturados, em que seis profissionais que atuam no processo de desenvolvimento de coleção, coordenadores ou analistas, detinham conhecimento para distinguir e identificar momentos em que a colaboração externa influenciou.

Nesse contexto, visualizaram-se duas possíveis proposições: i) para ocorrer a influência de colaboradores externos, as fases do PI devem ser desagregadas pelo escopo proprietário, ou seja, elas podem ser abertas ou fechadas, realizadas pelos profissionais internos da empresas ou por fornecedores externos; ii) mesmo com a adoção de um processo de inovação aberto, as fases são dependentes e não sofrem influência de colaboradores externos, mantendo-se constante e igual, independentemente da relação com fornecedores. 
Para justificar esta pesquisa, olhou-se para a crescente adoção de fornecedores internacionais nos processos de produção de muitos produtos, ora por capacidade tecnológica, ora por redução de custos. Em vista da falta de adoção de gestão de inovação em alguns setores industriais, como é o caso da fashion industry, somada a constantes descrições de PI (Cooper, r99o; Wheelwright \& Clark, I992), que não se adaptam unicamente a esses cenários de colaboração, mesmo com a abertura do processo (Chesbrough, 2003), busca-se aqui identificar a existência de um processo em que as fases podem ser desagregadas para permitir melhor adequação do PI da organização ao ambiente e melhor atuação de outros canais presentes na cadeia de fornecimento.

A fashion industry, objeto de estudo desta pesquisa, possui representatividade no mercado nacional, sendo o segundo maior empregador entre as indústrias de transformação. Formada por mais de 32 mil empresas atuando no território nacional, para a Associação Brasileira da Indústria Têxtil e de Confecção (Abit, 2OI6), representa aproximadamente 5\% do PIB. Essa indústria gera produtos em forma de coleções sazonais ofertadas a cada seis meses, contendo vestimentas e acessórios variados no acabamento, tamanho e preço. Fazendo uso de diversas tecnologias, essencialmente low tech, esse setor se mostrou rico de informações para coletar, testar e validar o framework proposto.

Formado por sete momentos, será apresentado: i) uma descrição bibliográfica das abordagens de PI, como o stage-gate, o funil de inovação, a inovação aberta, a cadeia de valor e o modelo do fluxo de inovação global; ii) em seguida, são elaboradas as proposições; iii) logo depois é apresentada a abordagem metodológica utilizada; iv) na sequência, são discorridos os resultados das análises; v) apresenta-se a discussão dos resultados; e vi) por fim, encerra-se a pesquisa com as considerações finais.

\section{Referencial Teórico}

As mudanças tecnológicas são importantes e cruciais para o crescimento econômico, por meio do qual as empresas conseguem se manter atualizadas, realizando inovações tecnológicas para se diferenciarem num mercado competitivo tanto local, quanto global e glocal (Freeman \& Soete, 20o8; Schumpeter, I96I). A produção de 
inovação ocorre por multe estágios para transformar ideias em bens de consumo, serviços ou processos, que venham a gerar diferenciação e, por fim, vantagem competitiva (Silva et al., 2OI3). Para Tidd e Bessant (2OI5), um PI trata da gestão das entradas de informação e de conhecimento, com saídas de produtos e serviços, fazendo uso de instrumentos de controle para atingir objetivos, e de melhor uso dos recursos disponíveis. Para a eficácia dessa gestão, ela tem que atender à estrutura da organização, ao padrões de comportamento das equipes envolvidas e a um planejamento do negócio (Tidd \& Bessant, 20I5), o que dificulta a definição de um modelo de PI como único e eficiente para as diversas formas de gestão de inovação.

Os diferentes modelos de PI foram bem estudados e definidos por Rothwell (I994), que propôs cinco gerações de inovações tecnológicas associadas à evolução estratégica coorporativa entre os anos de 1950 e 1990. Para Silva et al. (2013), os modelos da primeira e da segunda geração são simples e lineares; enquanto, nos modelos da terceira geração, há combinações de tecnologia ou mercado para disparar o processo dentro da linearidade, com retorno entre as fases; já, na quarta geração, os modelos privilegiam atividades paralelas, auxiliadas por alianças; e, na quinta geração, a inovação é vista como um processo integrado entre relações no processo.

A primeira geração é representada por Cooper (1990) e Wheelwright e Clark (1992) com seus modelos intitulados Stage-Gate, que possuem portas de validação das fases do desenvolvimento e o Funil de Inovação que favorece a captação de ideias. O modelo de Stage-Gate é centrado no desenvolvimento de novos produtos (DNP). Por meio dele, Cooper (I990) descreve a necessidade de desmembrar o processo em estágios pré-determinados interfuncionais e paralelos, em que, no final de cada estágio, há um gate para controle e validação, que permite a checagem da evolução do processo e, consequentemente, a sua aprovação ou reprovação, podendo ser continuado, descontinuado, paralisado ou recomeçado (Silva et al., 20I3). Esse modelo é muito empregado em setores de alta complexidade tecnológica, conhecido por hard tech, como indústrias automobilísticas, farmacêuticas e de maquinários (Gavira, Ferro, Rohrich \& Quadros, 2007), e é construído no interesse de constantes checagens e aprovações, por fazer uso de grande quantidade de recursos investidos no processo.

\section{Revista Administração em Diálogo} ISSN 2178-0080 
O modelo de Wheelwright e Clark (I992), o Funil da Inovação, é descrito com a associação de que bons processos possuem "bocas" largas e gargalos estreitos, para facilitar a captação de ideias tanto internas quanto externas. Esse modelo se torna eficiente com o uso de filtros que selecionam as melhores ideias que receberão investimento de recursos quando implantadas (Silva et al., 20I3). Adequado para ambientes de escassez de recursos que normalmente dispõem de muitas ideias iniciais, é um modelo focado em indústrias e mercados de bens de consumo, pois necessitam de mais agilidade no lançamento de novos produtos para manterem competitividade em setores de baixa ou média tecnologia (Gavira et al., 2007; Silva et al., 20I3). Na Figura I, é possível observar a representação desse processo e de suas fases.

Figura I - Funil do Desenvolvimento de Inovação.

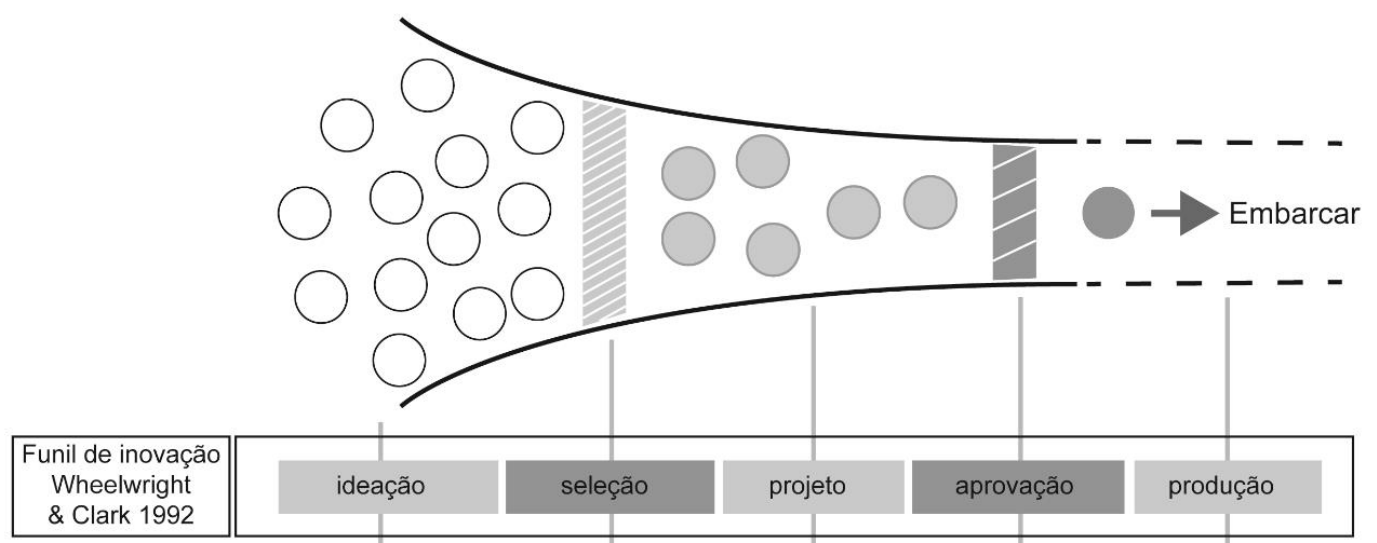

Fonte: Wheelwright e Clark (I992, p. I24).

Seguindo para a terceira e a quarta geração, os modelos de PI são mais abertos e integrados, envolvendo interações de setores, colaboração horizontal, flexibilidade e revisões de processo (Rothwell, I994). Os mais conhecidos são a inovação aberta, a cadeia de valor e o fluxo de inovação global.

O modelo de inovação aberta, de Chesbrough (2003), questiona a valorização do conhecimento e da tecnologia endógena e por consequência e necessidade de proteção da propriedade intelectual. Na Figura 2, é possível ver a representação das interações do processo com fontes de conhecimentos exógenas, externas ao processo, construída sobre cinco princípios: i) nem todo profissional inteligente e inovador trabalhará para uma única organização, por isso deve-se encontrar e explorar

\section{Revista Administração em Diálogo} ISSN 2178-0080 
conhecimento e experiências fora da empresa; ii) o P\&D externo pode ter valor significativo e o P\&D interno da organização necessita apropriar-se dele; iii) não é necessário ser o gerador da inovação para lucrar com ela; iv) fazer bom uso das ideias internas e externas torna-o vencedor; v) deve-se encontrar novas formas de lucrar com a propriedade intelectual gerada.

Para Gassmann (2006), o modelo de inovação aberta compactua com ambientes de baixas barreiras de proteção, em cenários globalizados, em que a adaptação é necessária. Lazzarotti e Manzini (2009) descrevem que a inovação aberta pode ocorrer de quatro formas diferentes, variando na necessidade de abertura do processo, são: i) inovadores fechados: são empresas que recorrem ao conhecimento externo somente para uma fase específica do processo; ii) colaboradores especializados: são empresas que sabem trabalhar com muitos colaboradores diferentes, mas todos concentrados na mesma fase do funil de inovação; iii) colaboradores integrados: são empresas que têm o processo de desenvolvimento aberto em todas as fases, mas somente para alguns parceiros; e iv) inovadores abertos: têm alta relação com parceiros e um processo de desenvolvimento aberto.

Figura 2 - Modelo de Inovação Aberta.

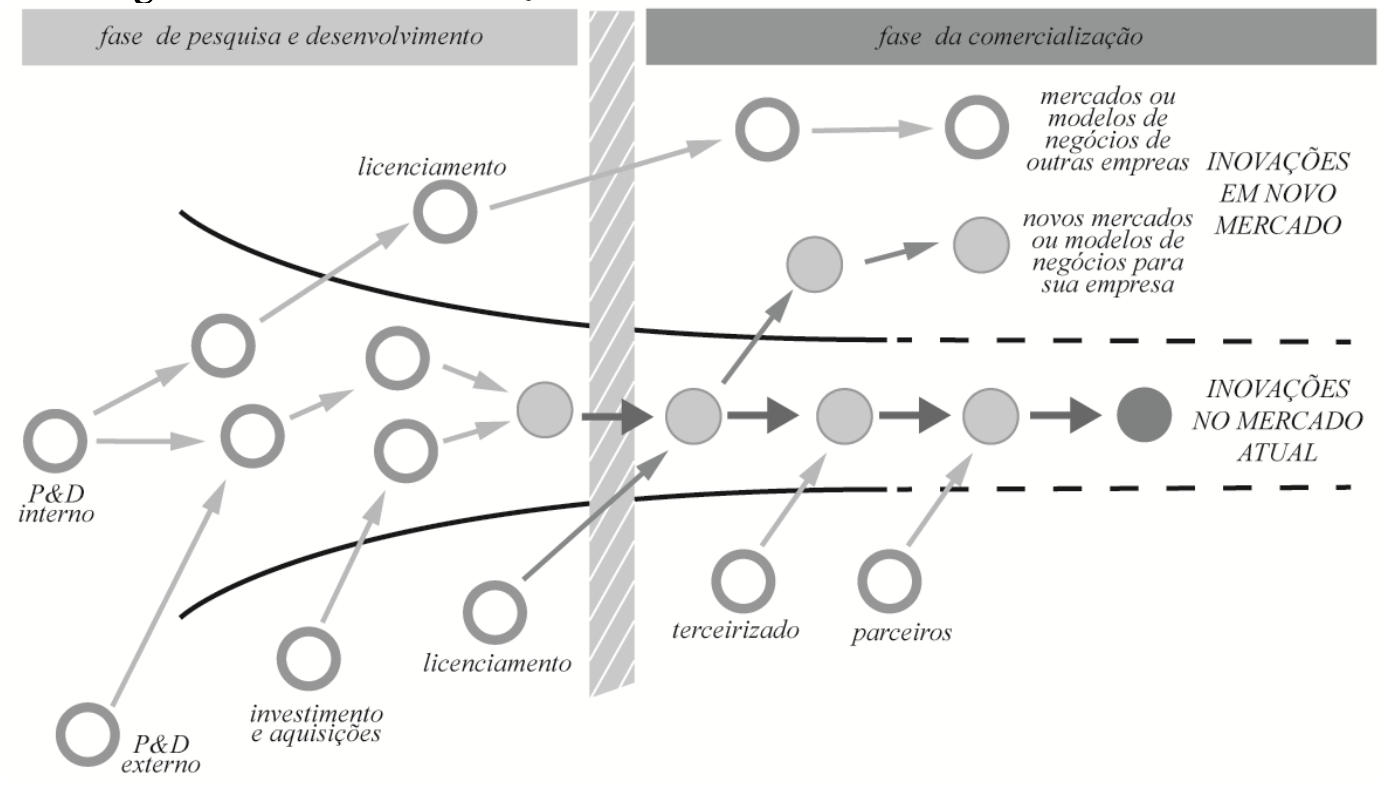

Fonte: Chesbrough (2003). 
O modelo de cadeia de valor de Hansen e Birkinshaw (2007) é indicado em situações em que a empresa tem como diretriz de negócio o bom atendimento ao cliente. Assemelhando-se com a 3 a geração de Rothwell (I994), o desenvolvimento de produto acontece por alinhamento e interligação entre setores, tendo uma visão ampla e integrada do PI da empresa (Demonel \& Marx, 20I5). O reconhecimento de interação entre setores e a fusão entre tecnologia empurrada pela empresa ou puxada pelo mercado geram uma lógica não linear e sistêmica na “cadeia” (Rothwell, I994). O modelo de cadeia de valor acontece em três etapas: geração de ideias, conversão das ideias em produção e a difusão das ideias. O que Hansen e Birkinshaw (2007) propõem nesse modelo é o envolvimento das dimensões estratégias e operacionais da empresa sem perder o seu valor principal, não havendo um bloco fraco ou mal gerido (Demonel \& Marx, 20I5).

O modelo do fluxo de inovação global de Von Zedtwitz, Corsi, Søberg e Frega (20I5) identifica, na descentralização do poder de decisão, a desagregação da propriedade sobre o PI, o que leva ao aumento da capacidade de criação e à produção de inovações em subsidiárias das organizações (Govindarajan \& Ramamurti, 2OII). Sendo comum encontrar subsidiárias em países emergentes ou em desenvolvimento, esse modelo traz um novo olhar sobre o PI, na atuação entre as fases e as localidades das subsidiárias. Com base nessa teoria, Von Zedtwitz et al. (2015) elaboraram o modelo de fluxo de inovação global, contemplando as quatro fases do ciclo de desenvolvimento de Vernon (I966): ideação, desenvolvimento, introdução em mercado primários e secundários. O conceito principal do modelo permeia a capacidade de os países em desenvolvimento gerarem e produzirem inovação, daí vem a associação do modelo com a inovação reversa. A inovação reversa é identificada nesse fluxo quando a inovação global, em algum momento durante o PI, passa de um país em desenvolvimento para um desenvolvido, sendo sua entrada, no entanto, iniciada em um país desenvolvido (Von Zedtwitz et al., 20I5).

\section{Proposição Teórica}

Com base em algumas características dos modelos descritos acima, propõe-se um framework em que as fases do PI são independentes, ocorrendo uma desagregação 
do escopo proprietário variável para cada fase. Para tal, foram identificadas as características favoráveis dos modelos que colaboram para a proposta: i) optou-se pela estrutura do funil de inovação de Wheelwright e Clark (1992), pois acredita-se que este é o modelo mais coerente e que tem convergência com processos de indústrias low tech; possuindo cinco etapas bem objetivas e distintas, facilita o reconhecimento e a similaridade com processos de diversos setores, como a fashion industry, ii) do modelo de inovação aberta de Chesbrough (2006), foi adotado o conceito de abertura de atuação com colaboradores externos nas fases do processo, reconhecendo o compartilhamento de fora para dentro e vice-versa no compartilhamento de conhecimento e tecnologias; iii) do modelo do fluxo de inovação global de Von Zedtwitz et al. (2OI5), foi adotada a descentralização do poder de decisão sobre as fases do PI.

O framework está representado na Figura 3, na qual é possível ver a relação proposta entre os modelos do funil de inovação, com a inovação aberta e o fluxo de inovação global. Tendo em vista objetivo de analisar se há desagregação da propriedade entre as fases do processo, este estudo trabalhará o framework sob duas proposições a serem validadas com a coleta e a análise dos dados: i) para ocorrer a influência de colaboradores externos, as fases do PI devem ser desagregadas pelo escopo proprietário, ou seja, elas podem ser abertas ou fechadas, realizadas pelos profissionais internos das empresas ou por fornecedores externos; ii) mesmo com a adoção de um processo de inovação aberto, as fases são dependentes e não sofrem influência de colaboradores externos mantendo-se constante e igual independentemente da relação com fornecedores. 
Figura 3 - Funil de Inovação Global Integrado.

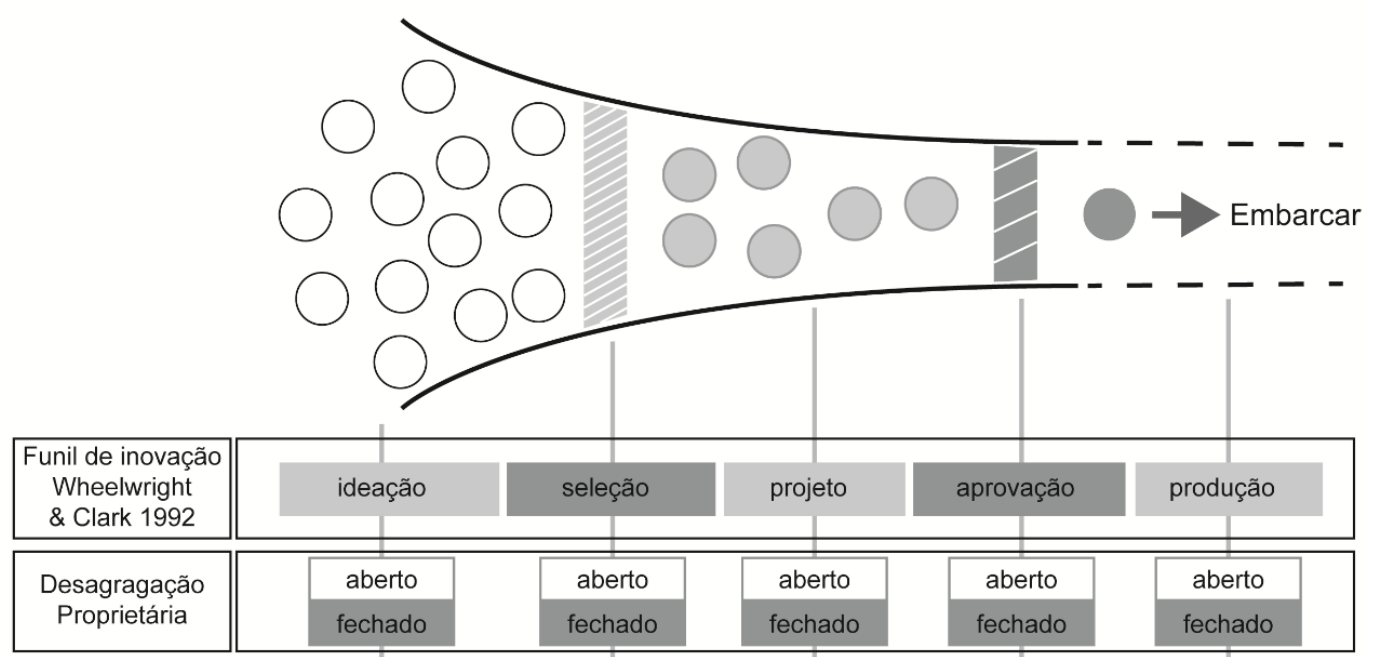

Fonte: Elaborado pelo autor.

\section{Método}

A abordagem metodológica adotada para este trabalho é a qualitativa, e foi desenvolvida pelo princípio dedutivo-indutivo, já que este é indicado na existência de uma fonte e consolidado por uma base teórica (Pozzebon \& Freitas, 1998). O estudo teórico deu bases para estabelecermos padrões que auxiliaram na construção do framework e por consequência a elaboração da pesquisa de campo, em vias de identificar as razões que emergem dos profissionais das empresas pela adoção de conhecimento externo. Para estudo de caso, utilizamos o modelo de Eisenhardt (I989) para entender o dinamismo presente nas empresas que realizam inovação aberta.

Fazendo uso de dados bibliográficos, documentais e de campo, esta pesquisa procura em "livros, periódicos e demais documentos escritos, as informações necessárias para progredir na investigação de um tema de real interesse” (Lima, 2005). Foram utilizadas fontes secundárias para a obtenção de dados sobre o setor da moda, como IBGE e Pintec. A pesquisa de campo foi realizada de forma sistematizada, pois, segundo Godoy (I995), a seleção e a organização devem estar livres de qualquer manipulação; para tal fizemos a elaboração de uma entrevista semiestruturada com I7 perguntas predefinidas, elaboradas dentro do conceito e das fases que fazem parte do modelo de funil de inovação de Wheelwright e Clark (1992).

Para a realização da análise dos dados, foi utilizado o software Atlas.ti, indicado por Godoi, Bandeira de Mello e Silva (2006), para fazer uso de codificações a serem

\section{Revista Administração em Diálogo} ISSN 2178-0080 
identificadas e quantificadas nos dados levantados. As codificações utilizadas no estudo estão presentes na Tabela I, na qual estão identificadas as categorias centrais como fases do processo, e as categorias específicas relacionam essas fases com a abertura de atuação, seguindo o proposto por Strauss e Corbin (2008) na utilização desse método.

Tabela I - Codificação das Categorias Usadas na Análise.

\begin{tabular}{c|c}
\hline CATEGORIA GERAIS & $\begin{array}{c}\text { DIMENSÃO - CATEGORIA } \\
\text { ESPECÍFICA }\end{array}$ \\
\hline $\begin{array}{c}\text { Fluxo de inovação } \\
\text { Wheelwright e Clark 1992 }\end{array}$ & $\begin{array}{c}\text { Desagregação Proprietária } \\
\text { Chesbrough 2006 }\end{array}$ \\
\hline \multirow{2}{*}{ - Pesquisa de Ideias } & 1.1 - Ideação Fechada \\
\cline { 2 - 2 } & 1.2 - Ideação Aberta \\
\hline \multirow{2}{*}{ - Seleção do Processo } & 2.1 - Seleção Fechada do Processo \\
\cline { 2 - 2 } & 2.2 - Seleção Aberta do Processo \\
\hline \multirow{2}{*}{3 - Projeto do Produto } & 3.1 - Projeto Fechado \\
\cline { 2 - 2 } & 3.2 - Projeto Aberto \\
\hline \multirow{2}{*}{ - Definição do Produto } & 4.1 - Definição Fechada \\
\cline { 2 - 2 } & 4.2 - Definição Aberta \\
\hline \multirow{2}{*}{5 - Produção do Produto } & 5.1 - Produção Fechada \\
\cline { 2 - 2 } & 5.2 - Produção Aberta \\
\hline
\end{tabular}

Fonte: Elaborado pelo autor.

Na busca por validação das análises dos dados, utilizou-se a técnica de interpretação Kappa, que busca testar o grau de confiabilidade e de precisão nas respostas dos entrevistados (Perroca \& Gaidzinski, 2003). O coeficiente Kappa auxiliou na identificação de quais entrevistados descrevem o PI da coleção de forma semelhante (Fonseca, Silva, \& Silva, 2OI3). Fazendo uso do software SPSS Statistics, identificou-se o valor de força de concordância entre os entrevistados. Para definir parâmetros das forças de concordância, utilizaram-se as nomenclaturas propostas por Landis e Koch (1977) para permitiram enquadrar os intervalos correspondentes de Kappa. Vide classificação na Tabela 2.

\section{Revista Administração em Diálogo} ISSN 2178-0080 
Tabela 2 - Mensuração das Concordâncias Kappa.

\begin{tabular}{c|c}
\hline Estatística Kappa & Força de Concordância \\
\hline$<0.00$ & Pobre \\
\hline $0.00-0.20$ & Fraca \\
\hline $0.21-0.40$ & Razoável \\
\hline $0.41-0.60$ & Moderada \\
\hline $0.61-0.80$ & Substancial \\
\hline $0.81-1.00$ & Perfeita \\
\hline
\end{tabular}

Fonte: Landis e Koch (1977, p. 165).

Para a coleta dos dados, foi utilizada uma empresa que aqui será identificada por Beta (na busca de manter sigilo), por se enquadrar no objeto de estudo da fashion industry. A empresa analisada teve a sua origem nos Estados Unidos, no estado de Nova York, tendo iniciado suas atividades no ano de I968 com a criação de sua primeira loja, que vendia as criações do estilista em pequenas quantidades para grandes e badaladas lojas de departamento. Na década de ı990, passou a internacionalizar suas vendas para outros países, como Espanha, Japão, França, Suíça e Cingapura. A subsidiária brasileira, que foi local da realização das entrevistas, completou II anos de atuação com a linha premium Jeans, conquistando 23 estados e um total de II5 lojas franquiadas no ano de 20i6. Com ofertas de linhas de roupas masculinas, femininas, infantil e de acessórios da marca, a empresa é uma marca geradora de tendência de moda.

\section{Resultados}

A coleta de dados foi realizada com seis profissionais do departamento de desenvolvimento de produto da empresa Beta. Como coordenadores e analistas, todos atuam diretamente no desenvolvimento de coleções para linhas jeans, masculino, feminino, infantil e acessórios. Após a realização das entrevistas e da análise dos dados pela quantificação de repetição de conteúdo específicos, foi possível chegar ao resultado que é apresentado na Tabela 3 . 
Tabela 3 - Resultado Quantitativo de quotations da empresa Beta

\begin{tabular}{|c|c|c|c|c|c|c|c|c|}
\hline \multirow[b]{2}{*}{$\begin{array}{l}\text { Categorias } \\
\text { Específicas }\end{array}$} & \multicolumn{6}{|c|}{ Quantidade de Quotation por Entrevista } & \multirow[b]{2}{*}{$\begin{array}{l}\text { Total de } \\
\text { Quotation/ } \\
\text { Categoria }\end{array}$} & \multirow[b]{2}{*}{$\begin{array}{l}\text { Maior Recorrência no } \\
\text { processo }\end{array}$} \\
\hline & TK_P & TK_M & PJ_F & BS_V & $\mathrm{Cl} \_\mathrm{I}$ & BC_J & & \\
\hline 1.1-Ideação Fechada & 4 & 12 & 4 & 9 & 8 & 5 & 42 & \multirow{2}{*}{$\begin{array}{l}\text { Fase de ideação } \\
\text { fechada }\end{array}$} \\
\hline 1.2-Ideação Aberta & 3 & 4 & 0 & 5 & 10 & 5 & 27 & \\
\hline 2.1-Seleção Fechada & 1 & 16 & 5 & 15 & 4 & 3 & 44 & \multirow{2}{*}{$\begin{array}{l}\text { Fase de seleção } \\
\text { fechada }\end{array}$} \\
\hline 2.2-Seleção Aberta & 1 & 9 & 3 & 4 & 3 & 0 & 20 & \\
\hline 3.1-Projeto Fechado & 7 & 9 & 3 & 9 & 24 & 10 & 62 & \multirow{2}{*}{ Fase de projeto aberto } \\
\hline 3.2-Projeto Aberto & 8 & 12 & 2 & 10 & 13 & 19 & 64 & \\
\hline $\begin{array}{l}\text { 4.1-Aprovação } \\
\text { Fechada }\end{array}$ & 2 & 12 & 6 & 4 & 6 & 5 & 35 & \multirow{2}{*}{$\begin{array}{l}\text { Fase de aprovação } \\
\text { fechada }\end{array}$} \\
\hline $\begin{array}{l}\text { 4.2-Aprovação } \\
\text { Aberta }\end{array}$ & 2 & 9 & 0 & 3 & 4 & 1 & 19 & \\
\hline $\begin{array}{l}\text { 5.1-Produção } \\
\text { Fechada }\end{array}$ & 14 & 1 & 6 & 10 & 1 & 0 & 32 & \multirow{2}{*}{$\begin{array}{l}\text { Fase de produção } \\
\text { aberta }\end{array}$} \\
\hline 5.2-Produção Aberta & 3 & 11 & 10 & 2 & 16 & 7 & 49 & \\
\hline $\begin{array}{l}\text { Total de quotation } \\
\text { por entrevista: }\end{array}$ & 88 & 176 & 77 & 131 & 178 & 110 & 760 & \\
\hline
\end{tabular}

Fonte: Elaborado pelo autor.

Com a análise do conteúdo, foi possível identificar os padrões do processo da empresa Beta pela recorrência de códigos identificados nas entrevistas. Para a fase de ideação, houve o dobro de indicações favoráveis para a realização do processo fechado, não correspondendo a muita abertura para a colaboração externa, possivelmente por ser uma fase na qual são identificadas tendências e novas tecnologias.

A fase de seleção foi semelhante, apresentando o dobro de recorrência em favor de uma fase fechada, adequado para uma atividade na qual há a necessidade de adequar as ideias ao processo produtivo da empresa. Porém, na fase de projeto, os resultados foram diferentes, favorecendo, por duas descrições, a realização da atividade de forma aberta; mas vale destacar aqui a proximidade entre aberto e fechado; provável decorrência da variedade de matérias-primas e tecnologias necessária para desenvolver os produtos da coleção, levando a busca por conhecimento externo.

Já, na fase de aprovação, é bem dispare a diferença que favorece a um processo fechado, novamente vindo a ser relacionada com o momento de decisão sobre quais produtos são aprovados e adequados para a produção e comercialização nas lojas da marca Beta. Por último a fase de produção favoreceu a uma atuação aberta, podendo

\section{Revista Administração em Diálogo} ISSN 2178-0080 
ser consequência da utilização de fornecedores externos para desenvolver o projeto, capacitando esses colaboradores externos a confeccionarem e produzirem os produtos.

Tabela 4-Agrupamentos das recorrências de categorias específicas da empresa Beta

\begin{tabular}{c|c|c|c|c|c|c}
\hline \multicolumn{6}{c}{ Resultado Geral das Quotations por entrevista da empresa Beta } \\
\hline $\begin{array}{c}\text { Categorias } \\
\text { Específicas }\end{array}$ & TK_P & TK_M & PJ_F & BS_V & CI_I & BC_J \\
Ideação & Fechado & Fechado & Fechado & Fechado & Aberto & Aberto \\
\hline Seleção & Fechado & Fechado & Fechado & Fechado & Fechado & Fechado \\
\hline Projeto & $\begin{array}{c}\text { Nenhuma } \\
\text { identificação }\end{array}$ & Aberto & Fechado & Aberto & Fechado & Aberto \\
\hline Aprovação & $\begin{array}{c}\text { Nenhuma } \\
\text { identificação }\end{array}$ & Fechado & Aberto & Fechado & Fechado & Fechado \\
\hline Produção & Fechado & Aberto & Aberto & Aberto & Aberto & Aberto \\
\hline
\end{tabular}

Fonte: Elaborado pelo autor.

Conforme constatou-se, são poucas as ocasiões em que os entrevistados apresentam concordância quanto ao processo (Figura 4). A única fase que apresentou total concordância entre os entrevistados é a de seleção, ao buscar possível relação com a estratégia da empresa; por Beta ser uma subsidiária da marca internacional, precisa adaptar todo um conceito de produto para o mercado nacional de consumo e estilo. Analisando esse resultado pela estatística Kappa (Tabela 5), os resultados de concordância alcançaram níveis que variam entre baixos, razoáveis e substancial, mas, no geral, diante desse resultado, é possível perceber que das I5 possíveis relações de concordância, dez estão de razoável para cima, uma razão de mais de $66 \%$ de dados confiáveis e precisos sobre o processo de desenvolvimento de coleção da empresa Beta.

Tabela 5 - Índice kappa geral intracasos da empresa Beta.

\begin{tabular}{c|c|c|c|c|c|c}
\hline \multicolumn{7}{c}{ Análise Kappa da empresa BETA } \\
\hline & $T K \_P$ & $T K \_M$ & $P J \_F$ & $B S \_V$ & $C I \_I$ & $B C \_J$ \\
\hline$T K \_P$ & 0,000 & 0,250 & 0,250 & 0,444 & - & 0,048 \\
\hline$T K \_M$ & 0,250 & 0,000 & 0,375 & 0,688 & 0,333 & 0,667 \\
\hline$P J \_F$ & 0,250 & 0,375 & 0,000 & 0,063 & 0,333 & 0,000 \\
\hline$B S \_V$ & 0,444 & 0,688 & 0,063 & 0,000 & - & 0,375 \\
\hline$C I \_I$ & - & 0,333 & 0,330 & - & 0,000 & 0,615 \\
\hline$B C \_J$ & 0,048 & 0,667 & 0,000 & 0,375 & 0,615 & 0,000 \\
\hline
\end{tabular}

Fonte: Elaborado pelo autor. 


\section{Discussão}

A empresa opta por realizar alguma fase do projeto externamente, na procura de desempenho e capacidades superiores de resultado, em relação ao que desempenha sozinha. Essa descoberta é decorrente dos resultados obtidos nas entrevistas, que após análise, confirmou a existência da variação entre as fases. Nos casos analisados, isso ocorre na fase de projeto, pela expertise que as confecções têm sobre os diversos tipos de tecido e de suas características técnicas.

No caso da fase de produção, foi unânime entre os entrevistados: o uso de fornecedores favorece ao acesso à tecnologia de capacidade de produção, e a expertise dos vendedores facilita o acesso a pontos de vendas. Utilizando as classificações para inovação aberta de Lazzarotti e Manzini (2009), teremos, em sua maioria, o modelo de colaboradores especializados para a empresa Beta, pois há alta relação com fornecedores no decorrer do processo, mas com baixa abertura para a produção de inovação, cuja abertura pode variar por tipo de linha de produto e por profissional que a gerencia.

Tabela 6 - Abertura do processo no caso Beta

\begin{tabular}{c|c}
\hline & BETA \\
\hline Categorias Específicas & Maior recorrência no processo da Beta \\
\hline IDEAÇÃO & Ideação Fechada \\
\hline SELEÇÃO & Seleção Fechado \\
\hline PROJETO & Projeto Aberto \\
\hline APROVAÇÃO & Aprovação Fechada \\
\hline PRODUÇÃO & Produção Aberta
\end{tabular}

Fonte: Elaborado pelo autor.

Analisando esses resultados pela perspectiva das proposições, observa-se que a primeira proposição, que trata de as fases ocorrerem de formas variadas, entre aberta e fechada, tornou-se verdadeira. Como visto na Tabela 3 , não ocorreu de faltar depoimentos para alguma das categorias específicas, o que nos leva a afirmar que todas as formas de atuação acontecem num único PI, corroborando com que as fases sejam abertas para influência de colaboradores externos.

\section{Revista Administração em Diálogo} ISSN 2178-0080 
Quanto à segunda proposição, que considerava as fases como dependentes, sendo adotado um único modelo de PI, com todas as fases fechadas ou todas abertas, ela se tornou falsa. Verificando a Figura 4, é possível notar que uma fase de seleção que ocorre de forma fechada não leva a uma fase de projeto fechada, e sim aberta. O mesmo ocorreu com as fases subsequentes que voltaram a ter a aprovação fechada e a produção aberta. Constatou-se, que mesmo se tratando de um processo, em que a finalização de uma atividade leva ao início de outra, isso não fica diretamente associado com a forma com que foi realizada a fase. Identificamos, pelas entrevistas, que em cada fase os recursos utilizados são direcionados para a finalização da atividade. Aqui entendemos que a definição do modelo unicamente aberto ou fechado não é mais válido e possível para descrever o PI que uma empresa venha a adotar, com base nesse caso da fashion industry.

Figura 4-Comparativo intracaso aplicado no funil de inovação aberta gradual

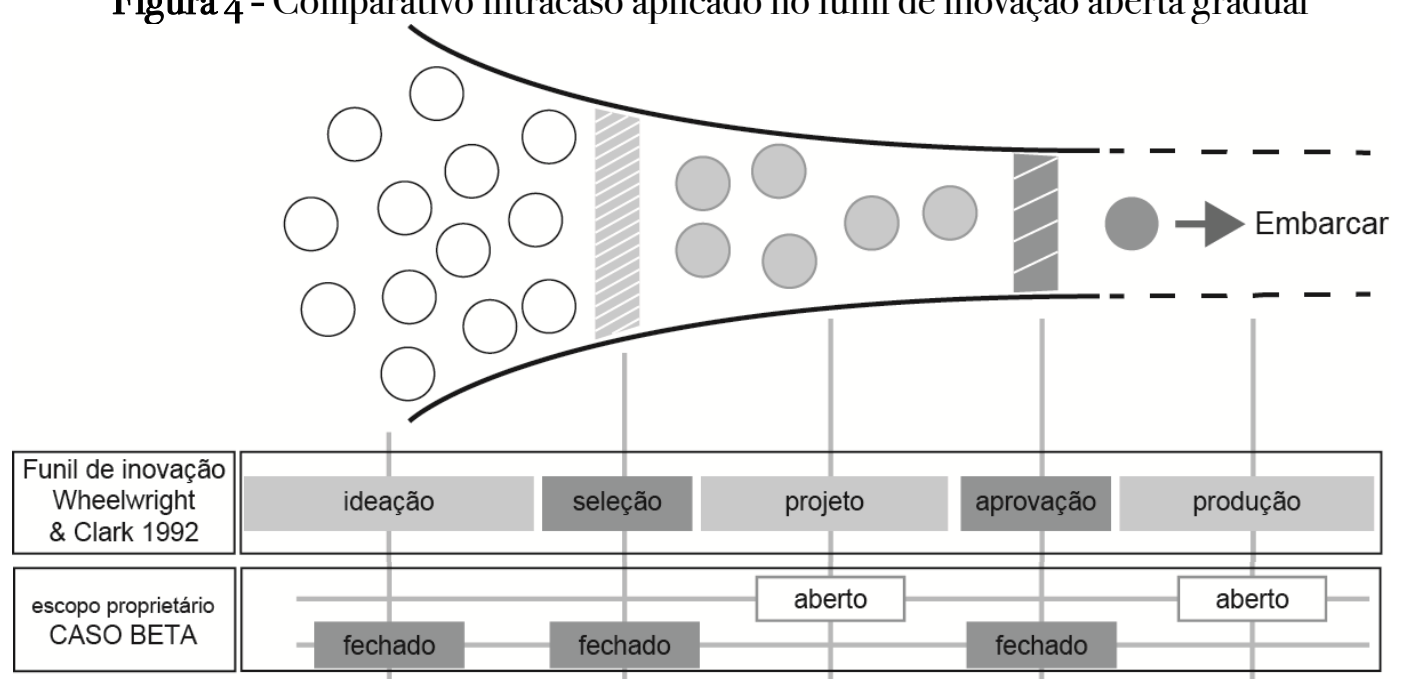

Fonte: Elaborado pelo autor.

\section{Conclusão}

Nesta pesquisa, procurou-se entender a gestão do PI de uma organização e sua relação com a participação e colaboração de fornecedores nesse processo. Para analisar essa relação, fez-se uso de um framework que engloba teorias de funil de inovação, inovação aberta e fluxo de inovação global. Com base nessa PI proposta, elaboraram-se questões para levantamento de dados que, posteriormente, foram analisados e interpretados.

\section{Revista Administração em Diálogo} ISSN 2178-0080 
Quanto ao problema de identificar qual a influência da colaboração externa no processo de desenvolvimento de produto inovador, ela foi respondida com base nos resultados encontrados nas entrevistas realizadas e nos dados analisados, que apontaram para uma influência direta no PI, que necessita ser levado em consideração pela gestão que venha a adotar uma estratégia de inovação.

Como vimos nos resultados, o processo pode ser mutável ou adaptável de acordo a forma que a organização se relaciona com os fornecedores, havendo a necessidade de considerar a abertura de fases que apresentam melhor resultado quando ocorre a atuação de colaboradores externos.

Após analisarmos como o PI pode ser adaptado para a desagregação proprietária, identificamos que a abertura de atuação externa à organização pode ter o escopo aumentado para o contexto global. Pode ocorrer de uma fase ser aberta por colaboração de fornecedores internacionais, levando o escopo de análise para uma ampliação territorial, em que também ocorreria uma desagregação geográfica dessa fase. Essa observação só foi possível após a análise as entrevistas, por meio da qual se notou que, em alguns casos, os entrevistados descreviam utilizar fontes de conhecimento e ideias presentes em lugares como Barcelona, Nova York e Paris. Cabendo aqui uma sugestão para trabalhos futuros.

Quanto aos limites desta pesquisa, ela está relacionada ao estudo realizado somente com um caso, havendo a necessidade de coleta de mais duas empresas do ramo de fashion industry para se ter mais dados comparativos sobre práticas de gestão de PI. Vale ressaltar que a adoção das fases do funil de inovação, de Wheelwright e Clark (I992), como base para a construção do framework, favoreceu a correlação do processo da organização com um processo teórico já conhecido, o que facilitou a análise e o estudo do caso. Mas aqui também encontramos mais uma colaboração para estudos futuros utilizarem este modelo: proposta para analisar o PI de organizações que atuam em outros setores industriais.

\section{Referências}

Chesbrough, H. W. (2003). The era of open innovation. MIT Sloan Management Review, Spring. 
Cooper, R. G. (1990). Stage-gate systems: a new tool for managing new products. Business Horizons, 33(3): 44-54.

Corbin, J., \& Strauss, A. (2008). Basics of qualitative research: Techniques and procedures for developing grounded theory. Thousand Oaks.

Demonel, W., \& Marx, R. (20I5). Gestão da Cadeia de Valor da Inovação em ambientes de baixa intensidade tecnológica. Production(ahead).

Eisenhardt, K. M. (1989). Building Theories From Case. Academy of Management Review, I4(4): I9.

Fonseca, R., Silva, P., \& Silva, R. (20I3). Acordo inter-juízes: O caso do coeficiente kappa. Laboratório de Psicologia, 5(I): 8I-90.

Freeman, C., \& Soete, L. (2008). A economia da inovação industrial. Campinas: Editora da Unicamp.

Gassmann, O. (2006). Opening up the innovation process: towards an agenda. $R \& D$ Management, $36(3): 223-228$.

Gavira, M. d. O., Ferro, A. F. P., Rohrich, S. S., \& Quadros, R. (2007). Gestão da Inovação Tecnológica: uma análise da aplicação do funil de inovação em uma organização de bens de consumo Revista de Administração Mackenzie, 8(I): 77-IO7.

Godoi, C. K., Bandeira de Mello, R., \& Silva, A. d. (2006). Pesquisa qualitativa em estudos organizacionais: paradigmas, estratégias e métodos. São Paulo: Saraiva.

Godoy, A. S. (1995). Introdução à pesquisa qualitativa e suas possibilidades. Revista de Administração de Empresas, 35(3): 57-63.

Govindarajan, V., \& Ramamurti, R. (2OII). Reverse innovation, emerging markets, and global strategy. Global Strategy Journal, I(3-4): I9I-205.

Hansen, M. T., \& Birkinshaw, J. (2007). The innovation value chain. Harvard Business Review, 85(6): I2I.

Landis, J. R., \& Koch, G. G. (I977). The measurement of observer agreement for categorical data. Biometrics, I59-I74.

Lazzarotti, V., \& Manzini, R. (20o9). Different modes of open innovation: a theoretical framework and an empirical study. International Journal of Innovation Management, I3(4): 6I5636 .

LIMA, E. d. O. (2005). Métodos qualitativos em administração: teorizando a partir de dados sobre processos em uma recente pesquisa. Anais do EnANPAD.

Perroca, M. G., \& Gaidzinski, R. R. (2003). Avaliando a confiabilidade interavaliadores de um instrumento para classificação de pacientes: coeficiente Kappa. Revista da Escola de Enfermagem da USP, 37(I): 72-80.

Pozzebon, M., \& Freitas, H. M. R. d. (I998). Modelagem de casos: uma nova abordagem em análise qualitativa de dados. Anais do EnANPAD, 22.

Rothwell, R. (I994). Towards the Fifth-generation Innovation Process. International Marketing Review, II(I): 7-3I. 
Schumpeter, J. A. (I96I). Teoria do desenvolvimento econômico. Fundo de Cultura.

Silva, D. O. d., Bagno, R. B., \& Salerno, M. S. (2OI3). Modelos para a gestão da inovação: revisão e análise da literatura. Produção (ahead).

Tidd, J., \& Bessant, J. (2015). Gestão da inovação. Porto Alegre: Bookman Editora.

Vernon, R. (I966). International investment and international trade in the product cycle. The Quarterly Journal of Economics, 190-207.

Von Zedtwitz, M., Corsi, S., Søberg, P. V., \& Frega, R. (2OI5). A Typology of Reverse Innovation. Journal of Product Innovation Management, 32(I), I2-28.

Wheelwright, S. C., \& Clark, K. B. (I992). Revolutionizing product development: quantum leaps in speed, efficiency, and quality. Simon and Schuster. 